\title{
Erratum to: Promotion of sleep education in Asia: promotion of sleep education in Israel
}

\author{
Jean Askenasy ${ }^{1}$
}

Published online: 24 December 2015

(C) Japanese Society of Sleep Research 2015

\section{Erratum to: Sleep Biol Rhythms \\ DOI 10.1007/s41105-015-0013-y}

In the original publication there are 2 errors:

(1) the abstract mentioned that the 13 frontal lectures, covering physiological and pathological aspects of sleep at Tel-Aviv University instead of TechnionIsrael Institute of Technology, as it is mentioned in the text.
(2) The corresponding author had mistakenly included Dr. Baruch El-Ad as author.

\section{Acknowledgments}

I thank Dr. Baruch El-Ad for providing important information to the article. 